\title{
Relationship of maximum aerobic power output to productivity and absenteeism of East African sugar cane workers
}

\author{
C. T. M. DAVIES 1 \\ University Medical Faculty, Dar es Salaam, Tanzania
}

\begin{abstract}
Davies, C. T. M. (1973). British Journal of Industrial Medicine, 30, 146-154. Relationship of maximum aerobic power output to productivity and absenteeism of East African sugar cane workers. The relationship of the physiological responses to laboratory exercise on an upright bicycle ergometer and predicted maximum aerobic power output $\left(\dot{\mathrm{V}} \mathrm{O}_{2 \max }\right)$ to daily and season output has been investigated in 78 cane cutters aged 18 to 50 years working on the Kilombero sugar estate, Tanzania.

The results showed that the $\mathrm{VO}_{2 \max }$ was independent of absolute productivity in terms of kilotons of cane cut per season but positively correlated $(\mathrm{r}=+0.46)$ with daily output. There was a small but significant $(r=-0.32, P<0.001)$ negative association of $\dot{V}_{2} O_{2 a x}$ with the number of days that an individual voluntarily absented himself from the cane fields. The importance of these findings to the selection and training of personnel for the cane-cutting industry are discussed. It was suggested that the industry might consider the introduction of a simple exercise (step) test together with a medical examination and simple anthropometric measurements at the time of recruitment of workers at the beginning of the season.
\end{abstract}

It has now been generally accepted that aerobic power output $\left(\mathrm{V}_{2} \max \right)$ measured in the laboratory provides a useful and valid guide to an individual's exercise tolerance (Shephard, Allen, Benade, Davies, Prampero, Hedman, Merriman, Myhre, and Simmons, 1968). Indeed, much time and effort has been spent in various laboratories throughout the world in the study of methods of measurement and the biological significance of $\dot{\mathrm{VO}}_{2} \max$. From these studies it is clear that the $\mathrm{VO}_{2}$ max essentially reflects the ability of the cardiorespiratory system and working muscles to transport and utilize oxygen and thus measures the capacity of the body for sustained work. It is also known that the $\mathrm{VO}_{2} \max$ is affected by age, sex, physique, and training, and

1On leave of absence from: MRC Environmental Physiology Research Unit, London School of Hygiene, Keppel Street, London WC1, to which address correspondence should be sent. although none of these factors is in dispute, the vital question in the industrial situation as to whether the $\mathrm{VO}_{2}$ max is actually related to work output under realistic everyday conditions remains unanswered.

To my knowledge, the only attempt to study this problem has been that of Wyndham, Cooke, Munro, and Maritz (1964) in the gold mining industry in South Africa. They investigated 28 African miners who were daily involved in a heavy task loading rock underground. They found that although they could demonstrate significant differences in productivity and physical working capacity between the men in the group, no correlation existed between maximum aerobic power and physical performance. They concluded that psychological, rather than physiological, factors were the main determinants of productivity in the gold mine. Indeed, a later study (Wyndham and Cooke, 1964) showed that motivation, particularly in the 
form of the white European leadership, was the most important single factor in governing the output of the African worker.

Their study is of obvious importance to the field of industrial medicine but it is difficult to interpret on several counts. First, the numbers studied were small and the sample was not random but biased towards those subjects with high maximum aerobic power within a narrow range; 21 of the 25 subjects had $\mathrm{VO}_{2}$ max values in excess of the mean value found in their previous 'random' study of 350 Africans working in the gold mining industry in Johannesburg (Wyndham, Strydom, Morrison, Williams, Bredell, and Heyns, 1966). Secondly, the overall supervision of the African miners was being effected by Europeans and the output data were clearly affected by and related to this factor. The results of the investigation, therefore, cannot be directly applied to most developing and developed countries of the world where, particularly in the former case, the tendency has been to replace expatriate supervision of workers by indigenous personnel.

In the present study, the maximum aerobic power of 78 male African workers, aged 18 to 50 years, employed as cane cutters on a government-owned sugar estate in Tanzania, East Africa, has been investigated in relation to productivity (in terms of the daily amount of cane cut and earnings) and absenteeism throughout the six months of a cane-cutting season.

The study was conducted in two parts in a way similar to that originally described by Wyndham et al. (1964). In the first instance it was necessary to find a situation in which the productivity could be measured accurately, and to establish (1) whether large inter- and intra-subject variability existed in output, and (2) whether this variability was a random or consistent phenomenon enabling the high producers to be clearly identified. Once these two factors were established, the second part of the study was undertaken to investigate the relationship between physiological performance and cutting ability in the cane fields. At the same time an attempt was made to answer two subsidiary questions. Clearly, if it could be shown that productivity was related to certain physiological measurements in the laboratory then it would be important to devise a simple work capacity test which could be incorporated into any future selection training programme in the sugar industry. For this reason the cane cutters were given a simple exercise (step) test to perform at the time of their recruitment. In addition certain anthropometric measurements were taken at the beginning of May and again in December in order to assess the effects of cane cutting on the body size and composition of the workers during the season.

\section{Procedure}

The place chosen for the study was the Kilombero sugar estate, Kidato, Tanzania. The reasons for this choice were that the conditions at the estate offered an opportunity to measure not only the major physiological variables, but also the actual work performed in the cane fields for each individual worker in terms of tonnage of cut cane. The estate possessed an excellent medical service and small hospital, and careful records were kept of sickness and absenteeism from the cane fields. Both the unions and management of the estate cooperated wholeheartedly in the investigation and all subjects gave their informed consent before participating in the study.

The 585 sugar cane workers employed on the estate were first screened at the beginning of the season (Fig. 1) for age, weight, height, and blood haemoglobin (Table 1) and all were given a thorough medical examination, which included a simple work (stepping) capacity test. These measurements, except the step test, were routinely carried out each year at the estate at the beginning of the cane-cutting season. Subjects who were either outside the age range 18-50 years or had clinical signs of disease, which included severe parasitic infection and anaemia, were excluded. During this part of the study the inter-subject variability of the various parameters measured was established and records of the previous year's earnings were taken. Following the preliminary examination the cane cutters started to work on the estate and towards the end of the season (December) a further selection of subjects was made on the basis of output (tons of cane cut) and earnings from the beginning of the season. Fifty-eight young men aged 18 to 35 years were divided into three groups representing low, medium, and high outputs and earnings together with a group of 20 older men over 35 years of age; they were asked to attend the laboratory which for the purposes of the study had been

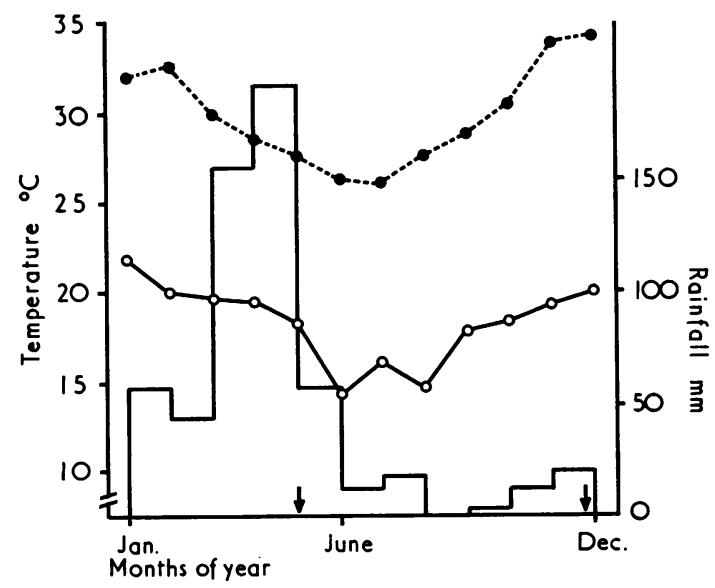

FIG. 1. Mean changes of maximum ( $\left.--0^{-}\right)$and minimum $(\mathrm{O}-\mathrm{O})$ temperature and rainfall (open columns) at the Kilombero sugar estate for 1972. The arrows mark the dates of (1) the preliminary survey and (2) the definitive study. 
TABLE 1

Physical Characteristics of a Sample of 285 Cane Workers from Total labour Force of 585 Men EMPloyed in CANE Fields

\begin{tabular}{|c|c|c|c|c|c|c|c|}
\hline \multirow[b]{2}{*}{ Age $(y r)$} & \multirow[b]{2}{*}{ Weight $(k g)$} & \multirow[b]{2}{*}{ Height $(\mathrm{cm})$} & \multirow[b]{2}{*}{$\Sigma s f(m m)$} & \multicolumn{2}{|c|}{ Circumference } & \multirow{2}{*}{$\begin{array}{c}H b \\
(\mathrm{~g} / 100 \mathrm{ml})\end{array}$} & \multirow{2}{*}{$\begin{array}{l}\dot{V} \mathrm{O}_{2} \max \\
\left(l \cdot \min ^{-1}\right)\end{array}$} \\
\hline & & & & $\operatorname{Arm}(\mathrm{cm})$ & Calf $(\mathrm{cm})$ & & \\
\hline $\begin{array}{r}26.8 \\
\pm 4.7\end{array}$ & $\begin{array}{r}62 \cdot 2 \\
\pm 5 \cdot 3\end{array}$ & $\begin{array}{r}165.9 \\
\pm 5.2\end{array}$ & $\begin{array}{r}23 \cdot 2 \\
\pm 4 \cdot 0\end{array}$ & $\begin{array}{r}26.2 \\
\pm 1.5\end{array}$ & $\begin{array}{r}33.7 \\
\pm 1.9\end{array}$ & $\begin{array}{r}11.8 \\
\pm 1.2\end{array}$ & $\begin{array}{r}2.92 \\
\pm 1.23\end{array}$ \\
\hline
\end{tabular}

$\Sigma$ sf $=$ sum of 4 skinfold thicknesses

set up close to the cane-cutting fields, in order that they could be investigated in greater detail.

On the first occasion at the laboratory the details of the experiment were explained to the subjects and they became accustomed to pedalling the bicycle and breathing through the mouthpiece. A sample of blood was taken for the determination of haemoglobin and the subject's age, height, weight, skinfold thickness, and limb volume, by both physical anthropometry and water displacement, were taken.

On the second occasion the subjects were required to pedal the bicycle with at least four consecutive workloads of increasing severity up to or near maximal levels of performance.

\section{Methods}

Details of the laboratory methods used in this study have already been given (Davies, 1968 and 1972; Davies, Barnes, and Godfrey, 1972) and the reader is referred to these publications for further information; only a brief outline of the methodology involved will be given here.

The initial (screening) tests on the workers included measurements of body weight using a standard hospital (Avery) scale accurate to within $\pm 250 \mathrm{~g}$, and body height to the nearest millimetre using a stadiometer. Skinfold thickness was measured at four sites (biceps, triceps, subscapular, and suprailiac) using a Harpenden skinfold caliper, and calf and biceps circumferences were determined with a tapemeasure. Haemoglobin $(\mathrm{Hb})$ concentration was estimated by the cyanmethaemoglobin method using an EEL photometer. In addition to these measurements each subject was required to perform a simple step test. This involved stepping on and off a 12 in $(300 \mathrm{~mm})$ high stool for 6 minutes at 30 steps per minute. The heart rate was measured by palpation during the first 10 seconds of recovery, and an estimate of maximum aerobic power output was made using the nomogram of Astrand and Ryhming (1954).

\section{Laboratory measurements}

During the more detailed investigation of the cane cutters in the laboratory the measurements of body weight, height, blood $\mathrm{Hb}$ concentration, and skinfold thickness were repeated. From this latter measurement lean body mass (LBM) was estimated using the method of Durnin and Rahaman (1967). In addition, leg volume (LV) was determined from measurements of height and circum- ference of the thigh and calf and from direct measurements of water displacement after the method of Jones and Pearson (1969).

Exercise was performed on a stationary bicycle ergometer. During work the subjects inspired from a low-resistance CD4 Parkinson-Cowan gas meter and expired through an Otis-McKerrow valve into a short piece of wide tubing connected to a mixing chamber (Davies and Shirling, 1967). A continuous form of test was given: after an initial period of 3 minutes' warm up the workload was raised every 2 minutes by $200 \mathrm{kpm} / \mathrm{min}$, the object being to cover the whole range of the subject's work capacity up to and including maximum effort. During the final minute at each workload, cardiac frequency was taken from a standard (Phillips) ECG recorder, respiratory frequency was counted, and inspired ventilation volume was recorded. At the same time samples of expired air were taken from the mixing chamber for subsequent analysis of $\mathrm{CO}_{2}$ and $\mathrm{O}_{2}$ content using a katharometer (Cambridge Instruments Ltd.) and a paramagnetic $\mathrm{O}_{2}$ analyser (Servomex Ltd.) respectively. The meters were calibrated at frequent intervals using gases of known concentration.

From these data oxygen intake $\left(\dot{\mathrm{VO}}_{2}\right)$ was calculated and the regression equations of cardiac frequency $\left(f_{H}\right)$ and minute ventilation $\left(\dot{\mathrm{V}}_{\mathrm{E}}\right)$ on $\dot{\mathrm{V}} \mathrm{O}_{2}$, and of $\dot{\mathrm{V}} \mathrm{O}_{2}$ on $\mathrm{f}_{\mathrm{H}}$ and workload (W) were computed for each subject individually and for the group as a whole. This enabled the results for exercise to be expressed in terms of a fixed $\mathrm{VO}_{2}$ of $1.51 . \mathrm{min}^{-1}$ (Cotes, Davies, Edholm, Healy, and Tanner, 1969) or a workload of $900 \mathrm{kpm} \cdot \mathrm{min}^{-1}$, and allowed the prediction of maximum aerobic power $\left(\dot{\mathrm{V}} \mathrm{O}_{2 \max }\right)$.

Details of each individual's daily earnings and canecutting capacity were obtained from the records of the Company.

\section{Results}

Inter-subject variability in physique, productivity, and work capacity and seasonal differences in earnings

The data for this part of the investigation were taken at the beginning of the season. Measurements of age, weight, and height were made on the complete cane-cutting labour force of 585 men and on a subgroup of 285 of these workers. Determinations 
of skinfold thickness, maximum calf and biceps circumference, blood haemoglobin, and physical working capacity (step test) were recorded. The aims of this part of the investigation were to establish whether (1) differences in body physique, fitness, and productivity did exist sufficient to justify a definitive study of the problem, and (2) the differences in cane-cutting performance in the fields were consistent from season to season. It will be seen (Table 1 and Fig. 2) that large differences do indeed exist for all parameters measured except blood haemoglobin but the figures for this parameter are not truly representative as all workers with a haemoglobin value less than $50 \%$ normal were eliminated before the investigation.

The mean weight, height, sum of four skinfold thicknesses, and biceps and calf circumferences are similar to those shown in Table 3 of the definitive study and show a 5 to $20 \%$ variation. The predicted values of maximum aerobic power $\left(\dot{\mathrm{V}}_{2}\right.$ max $)$ which were calculated from the cardiac frequency responses to a simple exercise test ( $\AA$ strand and Ryhming, 1954) show a similar pattern of variation. The mean $\mathrm{VO}_{2}$ max of the 285 cane cutters is 2.92 $\pm 1.231 . \mathrm{min}^{-1}$, which is closely in agreement with the average value found previously for sedentary men (Davies, 1971; Davies, Mbelwa, Crockford, and Weiner, 1973) and young adults (but not athletes) in training (Davies and Knibbs, 1971).

The data for earnings of the previous season were difficult, if not impossible, to obtain on the complete sample due to the African custom of changing names at irregular intervals of time. Reliable details of the productivity of $\mathbf{3 2}$ men included in the present study are shown (Fig. 2). The values range from 40 to 170 kilotons of cane cut per season and clearly show that the productivity of individual workers is a consistent phenomenon, each man maintaining approximately his rank order from one season to the next. The correlation between the productivity figures of the 1971 and 1972 season is $r=+0.73$.

A subsample of 78 cane cutters out of the $585 \mathrm{em}$ ployed by the sugar estate was studied in the labora-

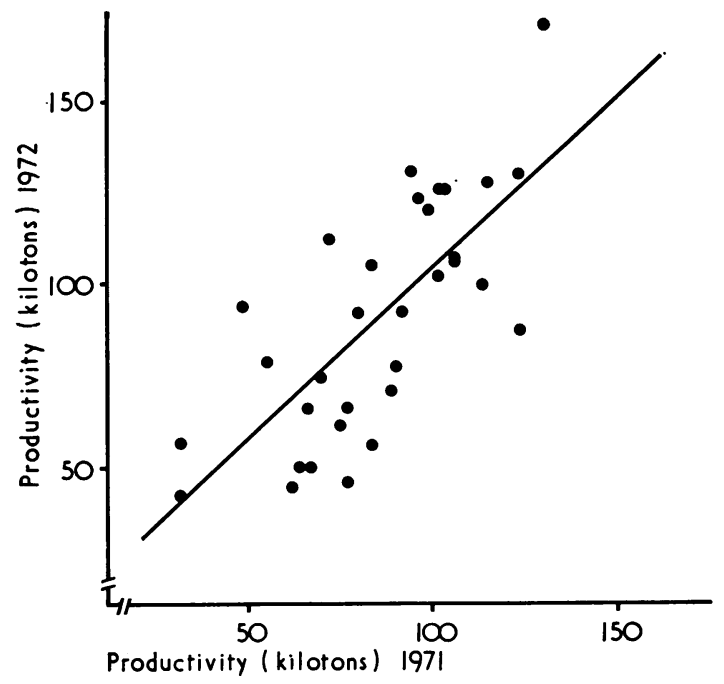

FIG. 2. Relationship of productivity in 1972 and 1971. The regression equation is of the form: $y(1972)=9.09$ $+0.956 x$ where $y=$ productivity in 1972 season, and $x=$ productivity in 1971 season $(r=+0.73 ; \mathrm{P}<0.001)$.

tory towards the end of the cutting season (Fig. 1). They were divided into four groups (Table 2): group 1, high producers (mean output 3.51 kilotons/ day); group 2, medium producers (mean output 3.04 kilotons/day); group 3, low producers (mean output 2.60 kilotons/day); and group 4 , men over 35 years of age. The physical characteristics of the men are given in Table 3.

\section{Physiological responses to exercise}

For a given workload of $900 \mathrm{kpm} . \mathrm{min}^{-1}$ the oxygen intake $\left(\mathrm{V}_{2}{ }_{900}\right)$ is identical for all four groups studied (Table 4) and agrees closely with previous work from this and other laboratories (Davies, 1971; Astrand, 1960). This is also true of the minute ventilation volume at the given $\mathrm{V}_{2}$ of 1.5 $1 . \mathrm{min}^{-1}\left(\dot{\mathrm{V}}_{\mathrm{E}_{1.5}}\right)$. The values range from 46 to 49

TABLE 2

Absolute and Daily Productivity (Total Cane Cut and Cane Cut per Day) and AbSenteeism from CANe FieldS

\begin{tabular}{c|c|ccc}
\hline Group & $n$ & $\begin{array}{c}\text { Absolute output } \\
\text { (kilotons) }\end{array}$ & $\begin{array}{c}\text { Relative output } \\
\text { (ktons/day) }\end{array}$ & Days absent \\
\hline 1 High producers . & 20 & $360 \cdot 6^{* * * 2,3,4}$ & $3 \cdot 51^{* * * 2,3,4}$ & $8 \cdot 7^{* * * 2,3,4}$ \\
2 Medium producers & 19 & $294 \cdot 7$ & $3 \cdot 04^{* * * 3}$ & $15 \cdot 2^{* * * 3}$ \\
3 Low producers . & 19 & $252 \cdot 2$ & $2 \cdot 60^{* * * 4}$ & $21 \cdot 1^{* * * 4}$ \\
4 Men over 35 years & 20 & $287 \cdot 4$ & $2 \cdot 95$ & $14 \cdot 7$ \\
\hline
\end{tabular}

${ }^{*} \mathrm{P}<0.05 ; \quad{ }^{* *} \mathrm{P}<0.01 ; \quad{ }^{* * *} \mathrm{P}<0.001$ 
TABLE 3

Physical Characteristics of 78 Subjects studied divided into 4 Groups: High (1), Medium (2), and Low (3) Producers and Older Men (4): (Mean \pm SD)

\begin{tabular}{|c|c|c|c|c|c|c|c|c|c|}
\hline \multirow{2}{*}{ Group } & \multirow{2}{*}{$n$} & \multirow{2}{*}{$\begin{array}{l}\text { Age } \\
(y r)\end{array}$} & \multirow{2}{*}{$\begin{array}{l}W t \\
(k g)\end{array}$} & \multirow{2}{*}{$\begin{array}{l}\mathrm{Ht} \\
(\mathrm{cm})\end{array}$} & \multirow{2}{*}{$\underset{(m m)}{\Sigma s f}$} & \multirow{2}{*}{$\begin{array}{c}L B M \\
(k g)\end{array}$} & \multirow{2}{*}{$\begin{array}{l}L V \\
(1 .)\end{array}$} & \multicolumn{2}{|c|}{ Circumference } \\
\hline & & & & & & & & $\begin{array}{l}\text { Biceps } \\
(\mathrm{cm})\end{array}$ & $\begin{array}{l}\text { Calf } \\
(\mathrm{cm})\end{array}$ \\
\hline 1 High producers & 20 & 25.6 & $62 \cdot 9$ & $167 \cdot 5$ & $25 \cdot 2$ & $55 \cdot 7$ & $12 \cdot 6$ & $27 \cdot 4$ & 34.9 \\
\hline 3 Low producers & $\begin{array}{l}19 \\
19\end{array}$ & $\begin{array}{l}25 \cdot 9 \\
27 \cdot 4\end{array}$ & $\begin{array}{l}61 \cdot 4 \\
59 \cdot 1\end{array}$ & $\begin{array}{l}166 \cdot 1 \\
165 \cdot 4\end{array}$ & $\begin{array}{l}25 \cdot 6 \\
24 \cdot 7\end{array}$ & $\begin{array}{l}54 \cdot 2 \\
52 \cdot 5\end{array}$ & $\begin{array}{l}12 \cdot 4 \\
11 \cdot 7\end{array}$ & $\begin{array}{l}27 \cdot 8 \\
27 \cdot 1\end{array}$ & $\begin{array}{l}34 \cdot 8 \\
34 \cdot 1\end{array}$ \\
\hline $\begin{array}{l}\text { yen over } 35 \\
\text { years of age.. }\end{array}$ & 20 & $\begin{array}{l}38 \cdot 8 \\
* * * 1,2,3\end{array}$ & $64 \cdot 4$ & $169 \cdot 8$ & $24 \cdot 2$ & $57 \cdot 3$ & $12 \cdot 8$ & $27 \cdot 7$ & $35 \cdot 0$ \\
\hline
\end{tabular}

$* * * \mathrm{P}<0.001$

1. $\min ^{-1}$, which are higher than those recorded for Europeans at similar work levels (Davies, 1971) but in accord with previous findings for Africans (Ojikutu, Fox, Davies, and Davies, 1972). The differences in cardiac frequency $\left(f_{\mathrm{H}_{1.5}}\right)$ at a fixed $\dot{\mathrm{VO}}_{2}$ are also small; the subjects in group 1 have a lower value than those in the other three groups but the difference is not significant. However, when the $\mathrm{f}_{\mathrm{H}} / \dot{\mathrm{VO}}_{2}$ data are used to predict the $\dot{\mathrm{V}} \mathrm{O}_{2} \max$, the high producers of group 1 have significantly $(P<0.001)$ higher aerobic power outputs than either group 3 or group 4 but not group 2 (Table 4). In relative terms (ml.min ${ }^{-1} \mathrm{~kg}^{-1}$ body weight) mean values of $\mathrm{VO}_{2} \max$ range from $51 \mathrm{ml} . \mathrm{min}^{-1} \mathrm{~kg}^{-1}$ (group 1) to $43 \mathrm{ml} \cdot \mathrm{min}^{-1} \mathrm{~kg}^{-1}$ (group 4), groups 2 and 3 having an intermediate value of approximately 48 ml. min $^{-1} \mathrm{~kg}^{-1}$.

Relationships of productivity to maximum aerobic power, physique, and body composition

For any given work output in the cane fields (kilotons of cane cut per season) the maximum aerobic power output as measured in the laboratory appears to be constant. The correlation between $\dot{\mathrm{VO}}_{2} \max$ and total output per season is $r=+0 \cdot 21$, and the slope of the line does not differ significantly from zero. Thus in absolute terms one can conclude that the workers' productivity is independent of their $\mathrm{VO}_{2} \max$. However, an important feature of the work in the cane fields is not only the output recorded in this way but also the number of days spent to produce a given output. In general, the high producers appear to spend less time (i.e., they work at a higher rate) to produce a given output and voluntarily absent themselves less from the cane fields (Table 2). The lower producer, on the other hand, has to work more days to achieve the same output and takes more unpaid rest days away from the fields. In Fig. 3 the data for $\mathbf{V O}_{2}$ max are plotted against daily productivity in kilotons per day. Although there remains a large scatter in individual values a definite positive association $(r=+0.46$; $P<0.001$ ) emerges. In Table 5 the principal indices of body physique and composition have been related to productivity in both relative and absolute terms in the form of a correlation matrix for groups 1 and 3 (subjects younger than 35 years) and group 4 (subjects older than 35 years). Correlation coefficients

TABLE 4

Submaximal Responses to Exercise and Predicted Maximum Aerobic Power $($ MeAN \pm SD)

\begin{tabular}{|c|c|c|c|c|c|c|}
\hline \multirow{2}{*}{ Group } & \multirow{2}{*}{$n$} & \multirow{2}{*}{$\begin{array}{l}\dot{V O} \mathrm{O}_{2900} \\
\left(l . \mathrm{min}^{-1}\right)\end{array}$} & \multirow{2}{*}{$\begin{array}{c}\dot{V}_{E 1.5} \\
\left(l . \min ^{-1}\right)\end{array}$} & \multirow{2}{*}{$\begin{array}{c}f_{H}{ }_{1.5} \\
\text { (beats.min } \\
-1)\end{array}$} & \multicolumn{2}{|c|}{ Predicted $\dot{V} \mathrm{O}_{2} \max$} \\
\hline & & & & & $l . \min ^{-1}$ & $\underset{\min ^{-1}}{\operatorname{ml.kg}(\text { body wt })}$ \\
\hline $\begin{array}{l}1 \text { High producers ... } \\
2 \text { Medium producers } \\
3 \text { Low producers .. } \\
4 \text { Men over } 35 \text { years of age. . }\end{array}$ & $\begin{array}{l}20 \\
19 \\
19 \\
20\end{array}$ & $\begin{array}{l}2 \cdot 12 \\
2 \cdot 10 \\
2 \cdot 09 \\
2 \cdot 12\end{array}$ & $\begin{array}{l}46 \cdot 8 \\
45 \cdot 8 \\
48 \cdot 6 \\
48 \cdot 6\end{array}$ & $\begin{array}{l}118 \\
123 \\
124 \\
120\end{array}$ & $\begin{array}{l}3 \cdot 20 * * * 3,4 \\
2 \cdot 95 \\
2 \cdot 80 \\
2 \cdot 76\end{array}$ & $\begin{array}{l}51 \cdot 0 * * * 3,4 \\
48 \cdot 0 \\
47 \cdot 3 \\
43 \cdot 0\end{array}$ \\
\hline
\end{tabular}

$* * * \mathrm{P}<0.001$ 


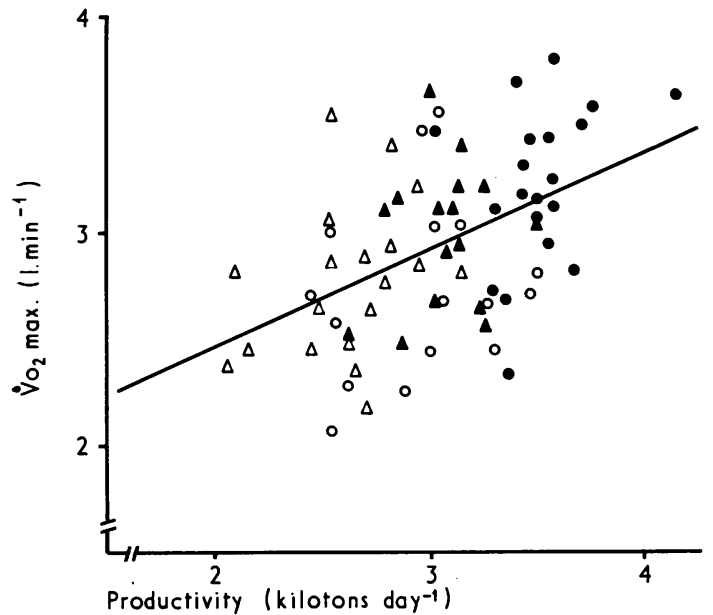

FIG. 3. Relationship of maximum aerobic power $\left(\mathrm{V}_{2} \max \right)$ to relative productivity (cane cut in kilotons per day). The regression is of the form: $y=0.449 x+1.573$ where $y=\dot{V O}_{2} \max$, and $x=$ relative productivity $(\mathrm{r}=+$ $0.46 ; \mathrm{P}<0.001): 0$ group $1 ; \Delta$ group $2 ; \triangle$ group 3 ; $\bigcirc$ group 4.

at or below the $5 \%$ level of significance have been shown. In terms of total productivity (output/ season) no association is shown with the various indices of body composition for either the younger or older subjects. However, for daily productivity (output/day) significant relationships are shown in the younger subjects for body weight $(0 \cdot 36)$, lean body mass $(0.36)$, and limb volume $(0.34)$, but in older subjects these relationships disappear. In groups 1 to 4 combined, the association of daily productivity with both weight and lean body mass is reduced to $r=+0.24$ and disappears completely for limb volume.

\begin{abstract}
Absenteeism
It is clear from Table 2 that the workers in group 1 absent themselves from the cane fields significantly less than those in groups 2 to 4 . Attendance at the fields is voluntary and if a worker absents himself, other than for sickness, he loses pay and this is recorded on his personal file. It is in the worker's own interest to attend the fields daily except Sunday and it is therefore of interest to find that the maximum aerobic power shows a very small $(r=-0.32)$ but significant $(P<0.001)$ negative relationship to absenteeism from the cane fields.
\end{abstract}

\section{Effects of cane-cutting season on body weight and} composition

Since measurements of the major indices of body size and composition were taken before and after the 1972 cane-cutting season, it is possible to assess the effects of six months' hard physical work on these parameters (Table 6). The cane cutters were responsible for finding their own food except for morning tea and maize porridge which was supplied by the Estate. Under these conditions there is a small but significant loss of body weight $(\mathrm{P}<0.05)$ and lean body mass $(P<0.01)$ which is accompanied by an increase $(P<0.001)$ in biceps and calf girth.

\section{Discussion}

In the developed countries of the world, although manual labour is still important in some industrial

TABLE 5

Correlation Matrix for Age, Weight, Height, Sum of 4 Skinfold Thicknesses, Lean Body Mass, Leg Volume, Maximum (Biceps and Calf) Circumferences, Productivity (Absolute and Relative) and Maximum Aerobic Power $\left(\dot{\mathrm{VO}}_{2 \max }\right)$ FOR GROUPS 1 TO 3 COMBINED AND GROUP 4

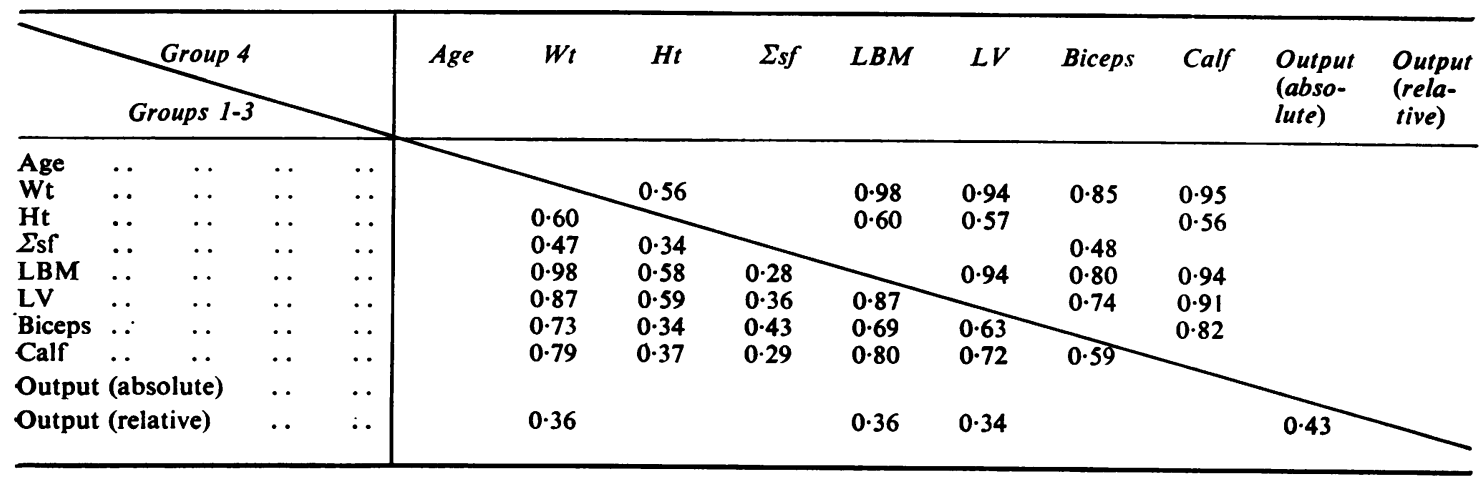


TABLE 6

Physical Characteristics of 37 Cane Cutters before and after a 6-Month Cane-Cutting Season (Mean \pm SD)

\begin{tabular}{|c|c|c|c|c|c|c|c|c|}
\hline & & & \multirow{2}{*}{$W t(k g)$} & \multirow{2}{*}{$H t(\mathrm{~cm})$} & \multirow{2}{*}{$\Sigma s f(m m)$} & \multirow{2}{*}{$L B M(k g)$} & \multicolumn{2}{|c|}{ Circumference } \\
\hline & & & & & & & Biceps $(\mathrm{cm})$ & Calf $(\mathrm{cm})$ \\
\hline Before $n=37$ & .. & . & $\begin{array}{l}63 \cdot 5 * \\
\pm 6 \cdot 8\end{array}$ & $\begin{array}{l}167 \cdot 4 \\
\pm 5 \cdot 6\end{array}$ & $\begin{array}{l}22 \cdot 5^{*} \\
\pm 3 \cdot 3\end{array}$ & $\begin{array}{l}57.06 * * \\
\pm 5.91\end{array}$ & $\begin{array}{l}26 \cdot 3 * * * \\
\pm 1 \cdot 6\end{array}$ & $\begin{array}{l}34 \cdot 0^{* * *} \\
\pm 2 \cdot 1\end{array}$ \\
\hline After $n=37$ & .. & .. & $\begin{array}{r}62 \cdot 1 \\
\pm 7 \cdot 4\end{array}$ & $\begin{array}{l}167 \cdot 2 \\
\pm 5 \cdot 8\end{array}$ & $\begin{array}{r}24 \cdot 4 \\
\pm 5.5\end{array}$ & $\begin{array}{r}55.51 \\
\pm 6.07\end{array}$ & $\begin{array}{r}27.6 \\
\pm 1.6\end{array}$ & $\begin{array}{r}35 \cdot 0 \\
\pm 2 \cdot 3\end{array}$ \\
\hline
\end{tabular}

${ }^{*} \mathrm{P}<0.05 ; \quad{ }^{* *} \mathrm{P}<0.01 ; \quad{ }^{* * *} \mathrm{P}<0.001$

spheres there has been a rapid move towards mechanization and automation over the past 20 years so that it may no longer be necessary for large sections of the community to exert themselves physically for prolonged periods in order to earn a living. In developing countries, however, conditions are very different. The vast majority of the population still depend mainly on subsistence farming to meet their daily requirements for food and shelter, and agriculture forms the governments' basic policy to meet the challenge of economic growth. In Tanzania, where the present study was undertaken, the move towards mechanization is slow and the need for human muscle power in various forms of rural and urban occupation remains. In this situation, it is of vital importance that occupational and industrial physiologists should strive towards a fuller understanding of the factors which may contribute to higher work output and increased efficiency so that once identified they can be incorporated into procedures for training and selecting personnel in order to raise the general productivity of the nation.

In the present study, which was designed to investigate the relationship between the physiological responses to exercise as measured in the laboratory to actual work output during a given task of cane cutting, one factor does clearly emerge: that there is a significant association between maximum aerobic power output $\left(\mathrm{V}_{2} \max \right)$ and the daily rate of working in the cane fields. High producers (group 1) possessed $\sim 20 \%$ advantage in $\dot{\mathrm{V}} \mathrm{O}_{2} \max$ over low producers (group 3), which was exactly paralleled by the difference in work output in the cane fields between the two groups (Table 2). Further, the decline in aerobic power output of the older subjects in group 4 is reflected in a reduced work output in the field. These results are clearly at variance with those of Wyndham et al. (1964), who showed no such relationship to exist in African Bantu workers employed in the gold mines. However, it is difficult to compare the two sets of data exactly because of the very different conditions in which they were collected. We agree with the importance they attach to such factors as skill, motivation, and leadership in contributing to given work output. In most human activities there is probably always a strong interplay between psychological and physiological factors which serve to confound the investigator. In the present investigation it must be stressed that the relationship we have found (Fig. 3) accounts for only $25 \%$ of the variance of productivity and clearly many other factors are involved. They may include, as well as those cited above, experience, attitudes, mood, the use of rest pauses, and state of acclimatization. Nevertheless our data suggest that the $\dot{\mathrm{VO}}_{2}$ max does provide a useful guide on a group basis to productivity and probably sets the upper limits of potential performance for the individual.

The maximum aerobic power is related not only to the rate of work in the cane field in the present study but also to absenteeism, a finding which is in agreement with the work of Lindén (1969). We found this aspect of the investigation difficult to study quantitatively. Our attempts to elucidate from the workers why they voluntarily absented themselves from the fields yielded many inconsistencies. However, one factor did emerge: the cane cutters often expressed the view that they simply did not feel up to the work and therefore, despite the loss of wages, would decide to spend the day in the compound. They did not feel sick or unwell in the accepted sense but were unable to face a heavy day's work in the heat. It may well be that the $\mathrm{VO}_{2}$ max not only sets the upper limit of potential performance but confers on those with a high value the ability to work at high rates for long periods of time. Thus they are able to work within their physiological capacity and are not forced to greater efforts than they are capable of making. They thereby avoid the cumulative day to day effects of fatigue, which leaves them free to pursue their jobs consistently throughout the canecutting season. Certainly the present data are in 
accord with this view and find support in the earlier work of Åstrand (1967). In her study of building workers she was able to establish a relationship between $\dot{\mathrm{VO}}_{2} \max$ and occupational workload spontaneously chosen by the individual if given a free choice. The workers in her study varied in $\mathrm{VO}_{2} \max$ from 2.19 to $3.631 . \mathrm{min}^{-1}$ (Table 4) but habitually chose a work rate corresponding to $\sim 40 \% \dot{\mathrm{VO}}_{2} \max$. This agrees closely with the rate of work she found in the laboratory beyond which both objective and subjective signs of stress occurred if prolonged for 6 to 8 hours (Åstrand, 1960).

It can be inferred from her findings that those subjects with a high $\mathrm{V}_{2}{ }_{2}$ max would achieve a greater absolute level of energy expenditure during the working day and presumably attain greater work output and productivity. She also showed that the older workers' $\mathrm{V}_{2} \max$ declined with age (Table 4) but the difference between the level of maximum aerobic power output of her old workers and ours should be noted. The older African cane cutters in the present study possess exceptional maximal aerobic power levels compared with Europeans of the same age (Davies, 1971). They show no increase in either body weight or body fat (Table 3), and their $\dot{\mathrm{V}}_{2}$ max values are similar to those for young healthy men of European descent (Cotes et al., 1969; Davies, 1971).

\section{Practical implications}

To be of practical use the factors which underlie productivity must have some predictive value. Clearly, as already mentioned, on an individual basis the predictive power of $\mathrm{VO}_{2}$ max to estimate productivity is useless. For a given $\mathrm{VO}_{2} \max$ value of, for example, $31 . \mathrm{min}^{-1}$ the confidence limits are such that we might expect his productivity in the cane fields to lie anywhere between 2.29 and 3.85 kilotons/ day. This covers the whole range of work outputs measured, from the highest in group 1 to the lowest in group 3. However, on a group basis, the picture is different. It will be seen (Table 5) that daily work output as well as being related to $\mathrm{VO}_{2}$ max is also associated with measurements of body size and composition. This may give some support to the procedure adopted in some industries (e.g., Chamber of Mines, South Africa) which entails hard physical work in order to eliminate those subjects with low body weight, LBM, or LV. But the data given in Table 3 would indicate that such measurements are not decisive in assessing potential productivity, and the power output to weight or LBM ratio may be a more important factor in cane cutting. In the canecutting industry selection is essential due to the overwhelming number of applications for the limited jobs available. It might therefore be useful at the time of recruitment to include a simple measure of work capacity together with body weight and LBM determinations at the time of the general medical examination, which should also include screening tests for parasitic infection and anaemia. Certainly it is our experience (Davies, Chukweumeka, and Van Haaran, 1972) that subjects with $\mathrm{Hb}$ levels less than $9 \mathrm{~g} / 100 \mathrm{ml}$ should be excluded. The work capacity test we gave in the laboratory is too sophisticated and time-consuming for practical purposes. The results of a simple step test (Table 1) may be more relevant. The test was extremely crude and again the individual values had little meaning but correlated well $(r=+0.57)$ with the $\dot{\mathrm{VO}}_{2} \max$ measured in the laboratory, in 32 cane cutters for whom data were available. The test is short, simple, requires a minimum of equipment, and could readily be incorporated into selection procedures.

Finally, the effects of a season's hard physical work on the body composition of the cane cutter are minimal but significant (Table 6) and they are quite contrary to studies which have been done on well-fed Europeans undergoing training (Carter and Phillips, 1969; Ribisi, 1969; Pollock et al., 1971). In the present investigation, body weight declined by 1.4 $\mathrm{kg}(\mathrm{P}<0.05)$ but this was surprisingly accompanied by an increase in fat $(P<0.05)$, a decrease in LBM $(\mathrm{P}<0.01)$, and an increase of biceps and calf circumferences $(P<0.001)$. These changes may be related to the effects of hard physical work on subjects who were existing on a subsistence diet rich in carbohydrate (mainly in the form of maize) and poor in animal protein, and fully underlines the need for further research work.

I am greatly indebted to Mr. David Mbelwa and $\mathrm{Mr}$. Theodore Kawamala for technical assistance throughout the study, and to Mr. Bitter, Mr. Van Castell, Dr. Mulundiang, Mr. Nytai, and Mr. Chiwango of the Kilombero Sugar Estate staff for their invaluable help and cooperation. Professor J. S. Weiner originally suggested that a study of physical working capacity and productivity might be profitable in the sugar cane industry, and Professor C. H. Wood helped to facilitate the project, especially in the early stages, and was a constant source of encouragement. I would also like to express my gratitude to the cane cutters for their cheerfulness and wholehearted involvement in the project.

\section{References}

Åstrand, I. (1960). Aerobic work capacity in men and women with special reference to age. Acta physiologica Scandinavica, 49, Suppl. 169.

_ (1967). Degree of strain during building work as related to individual aerobic work capacity. Ergonomics, 10, 293-303.

Åstrand, P. O., and Ryhming, I. (1954). A nomogram for calculation of aerobic capacity (physical fitness) from pulse rate during submaximal work. Journal of Applied Physiology, 7, 218-221.

Carter, J. E. L., and Phillips, W. H. (1969). Structural changes in exercising middle-aged males during a twoyear period. Journal of Applied Physiology, 27, 787-794. 
Cotes, J. E., Davies, C. T. M., Edholm, O. G., Healy, M. J. R., and Tanner, J. M. (1969). Factors relating to the aerobic capacity of 46 healthy British males and females, ages 18 to 28 years. Proceedings of the Royal Society of London Series B, Biological Sciences, 174, 91-114.

Davies, C. T. M. (1968). Limitations to the prediction of maximum oxygen intake from cardiac frequency measurements. Journal of Applied Physiology, 24, 700-706.

(1971). $\mathrm{O}_{2}$-Transporting system in relation to age. Clinical Science, 42, 1-13.

(1972). Maximum aerobic power in relation to body composition in healthy, sedentary adults. Human Biology, 44, 127-139.

- Barnes, C., and Godfrey, S. (1972). Body composition and maximal exercise performance in children. Human Biology, 44, 195-214.

- Chukweumeka, A. C., and Van Haaran, J. P. (1973). Iron deficiency anaemia. I. Its effect on maximum aerobic power output and responses to exercise of African males aged 17-40 years. Clinical Science (In press).

- and Knibbs, A. V. (1971). The training stimulus. Internationale Zeitschrift für angewandte Physiologie einschliesslich Arbeitsphysiologie, 29, 299-305.

-, Mbelwa, D., Crockford, G. W., and Weiner, J. S. (1973). Exercise tolerance and body composition in male and female Africans aged 18-30 years. Human Biology (In press).

-, and Shirling, D. S. (1967). The rapid sampling, storage and analysis of expired air. Ergonomics, 10, 349-360.

Durnin, J. V. G. A., and Rahaman, M. M. (1967). The assessment of the amount of fat in the human body from measurements of skinfold thickness. British Journal of Nutrition, 21, 681-689.

Jones, P. R. M., and Pearson, J. (1969). Anthropometric determination of leg fat and muscle plus bone volumes in young male and female adults. Journal of Physiology, 204, 63P-66P.
Lindén, V. (1969). Absence from work and physical fitness. British Journal of Industrial Medicine, 26, 47-53.

Ojikutu, R. O., Fox, R. H., Davies, C. T. M., and Davies, T. W. (1972). Heat and exercise tolerance of rural and urban groups in Nigeria. Proceedings of the International Conference-Human Biology of Environmental Change, Malawi 1971 (publ. I.B.P. London), pp. 132-144.

Pollock, M. L., Miller, H. S., Janeway, R., Linnerud, A. C., Robertson, B., and Valentino, R. (1971). Effects of walking on body composition and cardiovascular function of middle-aged men. Journal of Applied Physiology, 30, 126-130.

Ribisi, P. M. (1969). Effects of training upon the maximal oxygen uptake of middle-aged men. Internationale Zeitschrift für angewandte Physiologie einschliesslich Arbeitsphysiologie, 27, 154-160.

Shephard, R. J., Allen, C., Benade, A. J. S., Davies, C. T. M., di Prampero, P. E., Hedman, R., Merriman, J. E., Myhre, K., and Simmons, R. (1968). The maximum oxygen intake. An international reference standard of cardiorespiratory fitness. Bulletin of the World Health Organisation, 38, 757-764.

Wyndham, C. H., and Cooke, H. M. (1964). The influence of the quality of supervision on the production of men engaged on moderately hard physical work. Ergonomics, 7, 139-149.

,-- Munro, A., and Maritz, J. S. (1964). The contribution of physiological factors to the performance of moderately heavy physical work. Ergonomics, 7, 121-137. , Strydom, N. B., Morrison, J. F., Williams, C. G., Bredell, G. A. G., and Heyns, A. (1966). The capacity for endurance effort of Bantu males from different tribes. The South African Journal of Science, 62, 259-263.

Received for publication August 8, 1972.

Accepted for publication October 18, 1972. 